\title{
Natural Productivity, Morphometrics and Seasonal Distribution of Caulerva Racemosa
}

\author{
Tengku Said Raza'i ${ }^{1}$, Viktor Amrifo ${ }^{2}$, Imam Pangestiansyah Putra ${ }^{1}$, Try Febrianto ${ }^{1 *}$, Aidil Fadhli Ilhamdy $^{1}$ \\ ${ }^{1}$ Faculty of Marine Science and Fisheries, Universitas Maritim Raja Ali Haji, Tanjungpinang, Indonesia. \\ ${ }^{2}$ Faculty of Fisheries and Marine Science, Universitas Riau, Pekanbaru.
}

\begin{abstract}
Caulerva racemosa seaweed is a superior commodity with both ecological and socio-economical benefits. It is technologically developed into different products which include antioxidants, antibiotics, medicinal ingredients, cosmetics as well as other organic products and also used conventionally as food ingredients for human's consumption. Meanwhile, the presence of $C$. racemosa is observed to decrease as the exploitation rate is one of the factors affecting its stock in the nature. Changes in environmental conditions contribute majorly to its availability in aquatic ecosystems. Furthermore, natural factors in the form of seasonal changes that cause fluctuations in water dynamics are the main focus affecting its lifespan. The results showed that $\mathrm{C}$. racemosa growth parameters, which include percentage cover, productivity, together with morphometrics, failed to be significantly affected by seasonal changes. Meanwhile, the highest percentage cover was found during the northern monsoon, which has an average value of $37.99 \pm 7.67$ (Average \pm STDEV), while the lowest was during the eastern monsoons with $28.03 \pm 9.09$ respectively. The best morphometric size was during the northern monsoon with a tallus dimension of 0.25 with an average of $0.201 \pm 0.03$ and length of $0.825 \pm 0.16$, a stolon length of 2.09 with an average of $1.95 \pm 0.08$, 9 stolon grains with an average of $8 \pm 0.2$. However, the grain diameter, as well as the biomass, was $0.85 \mathrm{gr}$ and $0.054 \mathrm{gr}$ with an average of $0.825 \pm 0.22 \mathrm{gr}$ and the grain biomass was with an average of $0.040 \pm 0.01$ and $0.041 \mathrm{gr}$ with the best average stolon was $0.031 \pm 0.01 \mathrm{~g}$ in the western season. The results showed that $\mathrm{C}$. racemosa, which grows up in different seasons, having its highest productivity during the northern season and the lowest one was during the eastern season with an average value of $0.439 \pm 0.36 \mathrm{~kg} / \mathrm{m} 2$ as well as $0.326 \pm 0.37 \mathrm{Kg} / \mathrm{m} 2$, respectively
\end{abstract}

\footnotetext{
* Corresponding Author: try.febrianto@umrah.ac.id
} 


\section{Introduction}

The potential of the seaweed resources in Bintan Island are very large, having 15 species scattered along its coastal area (Radiarta et al., 2012). This condition is directly or indirectly strengthened by coastal communities of the Island due to its frequent use. Similarly, the Caulerva racemosa, which is a superior product, is a type of seaweed that is widely used and developed into different kinds of processed products.

C. racemosa contains several bioactive ingredients (Kumar et al. 2019; Nagaraj and Osborne, 2014), which are developed into cosmetic and processed food products (Pereira, 2018; Tapotubun et al. 2020). Furthermore, it is developed into feed for cultured fish (Putri et al. 2017), functioned as a waste bioremediation agent and also biofilter in integrated aquaculture activities (Paul and Nys, 2008; Pandya et al. 2017).

While local people of Bintan Island call the C. racemosa as "Latoh,"it has been exploited by the community for food and vegetables. Its benefits include high economic value with marketing into foreign countries as a primary and secondary source of income. Meanwhile, its presence in the nature is influenced by changes of the monsoons and also susceptible to change in physics as well as the chemistry of water, which affects its physiology, growth, together with reproduction (Harley, 2012). Furthermore, Oceanographic conditions which change along with the season, temperature variables, and nutrient supply (Sunny, 2017) affect the conditions of the algae communities (Duarte et al. 2017), including the type of C. racemosa.

In addition, another impact that threatens its existence is water pollution with increasing intensity in certain seasons. Similarly, its presence is influenced by water pollutants, such as oil spills (Chang et al. 2014; Yuewen and Adzigbli, 2018), marine debris, and other different types of pollution caused by human activities (Chung et al. 2017). Deducing from the existing conditions, preventive measures must be observed accordingly to protect $\mathrm{C}$. racemosa in the nature to support the coastal communities' livelihoods. Therefore, the characteristics of the C. racemosa study are needed to ascertain the impact of its existence in different seasons.

\section{Methodology}

\subsection{Location and Sampling Instruments}

This research was performed in the coastal waters of Bintan Island with the location distribution divided into seven areas including Teluk Bakau, Malang Rapat, Berakit, Beralas Pasir, Pengudang, Sakera, and Dompak (Figure 2). Furthermore, data collection was conducted from May 2020 to February 2021 based on seasonal changes, which included the East (February to April), South (May to July), West (August to October) as well as the North (November to January) seasons, respectively. Meanwhile, data distribution and the coverage of C. racemosa were collected by using some materials such as Quadrant plot 0.5 x $0.5 \mathrm{~m} 2$, Underwater camera (Canon D30 82 / 25m rated depth), GPS (Garmin GPSMAP 78S), Scuba Set (Amscud), oven (memmert UN 55), analytical scales (kern ABJ 220 0.001), aluminum foil, plastic samples, label paper, and sample boxes.

Captions should be typed in 9-point Times. They should be centred above the tables and flush left beneath the figures.

\subsection{Sampling Method}

The distribution and the cover of data collection were performed using the transect plot method (Llamas et al. 2018; Lodola, 2013; Melsasail et al. 2018; Das et al. 2018) conducted on a $50 \times 50 \mathrm{~cm} 2$ plot (Melsasail et al. 2018; Llamas et al. 2018). Furthermore, the coverage of C. racemosa was performed by taking pictures using an underwater camera, subsequently analyzing the cover level (Das et al. 2018).

Furthermore, the C. racemosa's productivity was tested using the Gravimetry biomass method (Rehena, 2009; Arnol et al., 2019). Meanwhile, the measuring method of productivity was in line with drying the biomass (gravimetry biomass) value using an oven dryer at $60^{\circ} \mathrm{C}$ for 48 hours. Morphometric data refered to Pusvariauwaty et al. (2015) by cutting 1 to 3 clumps of C. racemosa with repeated observations of 5 to 6 times each. The data collected were thallus diameter (DT), length (PT) as well as biomass (BT) and a number of stolon grains (JBs), its length (PS), diameter (DBs), and biomass (BS) (Pusvariauwaty et al. 2015; Notowinarto et al. 2015).

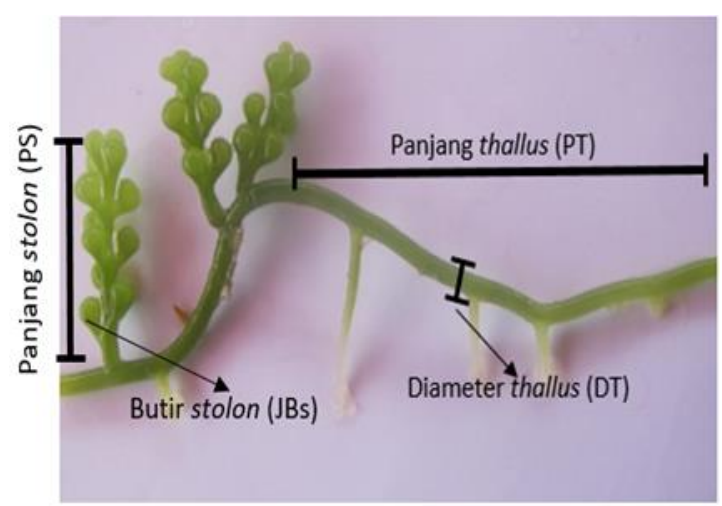

Fig. 1. Schematic measurement of the morphometric of C. racemosa

\subsection{Data Analysis}

Percentage cover and biological productivity of $\mathrm{C}$. racemosa's calculation were in line with Llamas et al. (2018). Furthermore, determination of the percentage value of cover, the $\mathrm{C}$ equation as a Cover Area (\%) divided on the Total Sampling Area (m2). Meanwhile, the calculation of natural productivity was performed using gravimetric biomass approach with the equation of $\mathrm{B}=\mathrm{W} / \mathrm{a}$ (Runtuboi et al. 2018; Rehena, 2009; 
Arnol et al. 2019), where B (gr/m2) was the biomass, W (gr) was the dry weight, and a (m2) was the sampling area. While the data were analyzed by making the average value and standard deviation (STDEV), differences between parameters were tested with a comparative analysis using the SPSS 20.0. After that, the data between season differences were analyzed by one-way ANOVA at a significant level of $\mathrm{P}<0.05$ for all parameters, and the relationship between percentage cover of C. racemosa as well as water quality parameters was tested using the Pearson correlation analysis.

\section{Result and Discussion}

\subsection{Percentage of Cover and Natural Productivity of C. Racemosa}

The percentage cover describes the natural conditions of C. racemosa in the aquatic ecosystem. In addition, a higher value indicates a good conditions, while decreasing value indicates a change in environmental factors. Based on the results, coverage data and cover value were grouped into three cover classes which are 0 to 33 (low), 33 to 67 (moderate), and 67 to 100 (high) (Figure 2).

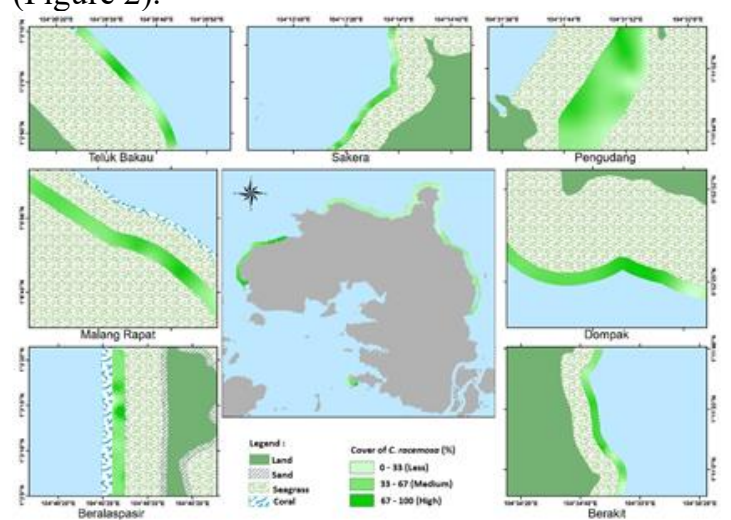

Fig. 2. Distribution and density of C. racemosa on the coastal waters of Bintan Island. A light blue is a low density $(0-33 \%)$, light green is medium-density (33$67 \%)$, and green is high density $(67-100 \%)$.

Furthermore, the results showed that characteristics of waters were factors affecting the percentage cover of C. racemosa. Figure 2 also explained that open water had a lower cover value when compared to a more secure locations. While the low cover condition of $\mathrm{C}$. racemosa in an open water was influenced by high currents and wave's dynamics, the oceanographic were not high in protected areas. Denny and Gaylord (2002) said that the climate, the waves, the current are the factors that affect the survival, size and distribution of marine algae. In addition, Burel et al. (2019) also reported that an increase in hydrodynamic intensity (waves and currents) affects changes in cover. However, Jonsson et al. (2006) reported that strong waves and currents conditions cause holdfast marine algae to be carried away by oceanographic dynamics, especially in types of algae with no solid roots. Furthermore, Burel et al. (2019) discovered that macroalgae canopy percentage decreased alongside with an increase in wave's hydrodynamics. Moreover, in the intertidal area, the value is $45 \%$, while the cover condition dropped to $42 \%$ in the coastal areas with stronger waves and currents.

Table 1. Percentage of C. racemosa cover by season Percentage of cover (Average \pm STDEV) $\quad$ Average of Condition

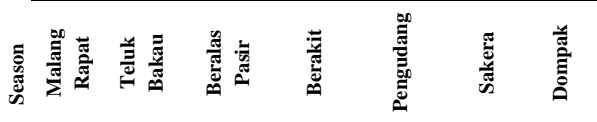

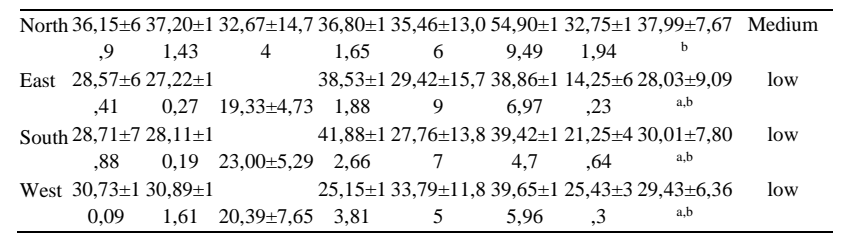

Table 2. Natural productivity of C. racemosa cover by season

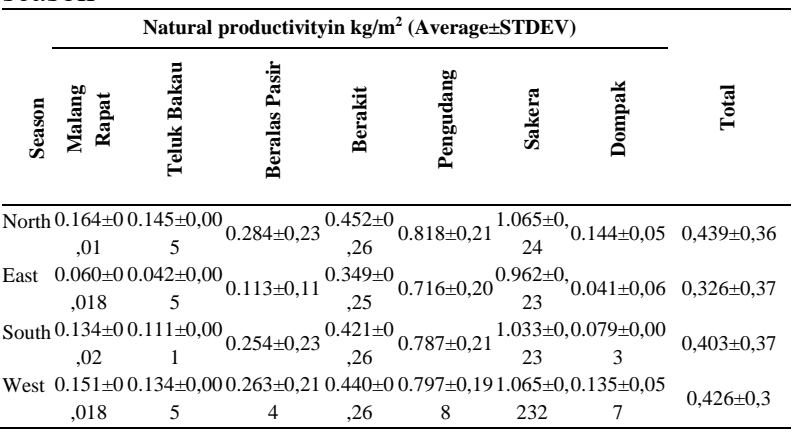

Table 1 showed that the total cover (\%) values of $\mathrm{C}$. racemosa ranging from 23.42 to $35.59 \%$ with a mean of $31.37 \%$ that was included in low coverage conditions. While these were differentiated in line with the difference in the period, the northern and the eastern monsoon had the highest and lowest cover value, which were $37.9 \pm 7.67 \%$ (medium) and $28.03 \pm$ $9.09 \%$ (low) respectively. Meanwhile, the cover percentage during the east, south and west monsoons had a value that was not significantly different, while during the northern monsoon was different from other seasons. Furthermore, Table 2 showed that the highest natural productivity value occurs in the northern and the lowest in the eastern season with a value of $0.439 \pm$ $0.36 \mathrm{~kg} / \mathrm{m} 2$ and $0.326 \pm 0.37 \mathrm{~kg} / \mathrm{m} 2$, respectively. In addition, the data showed that there was link between changes in cover value and natural productivity of $\mathrm{C}$. racemosa which was also listed in Figure 3. 

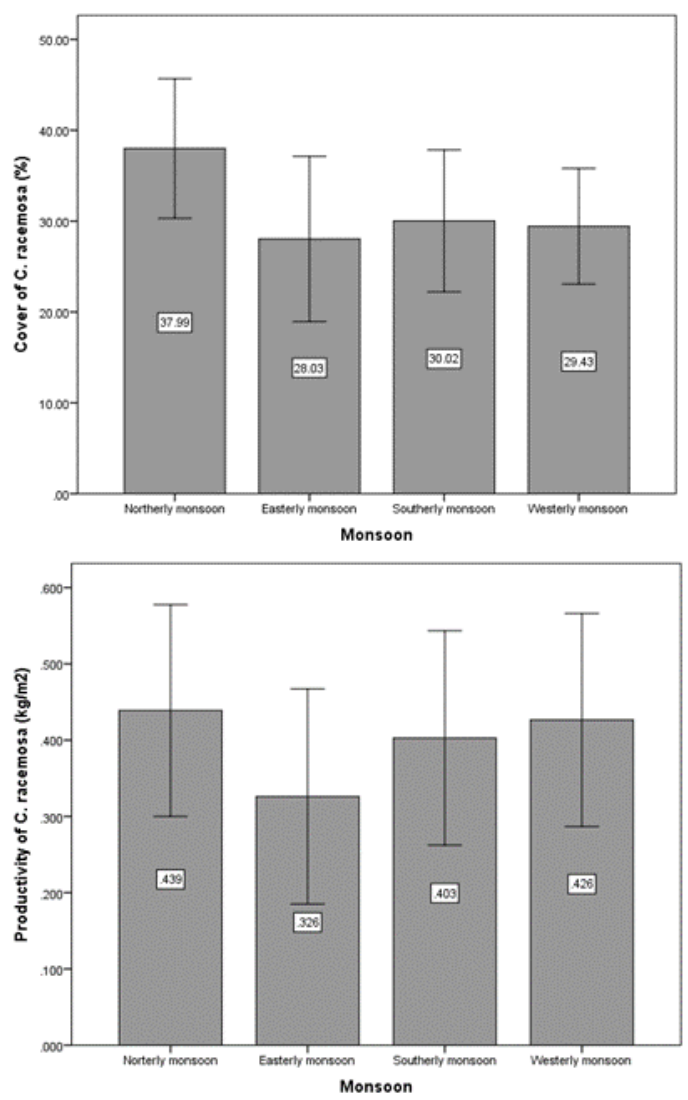

Figure 3. Average and productivity cover of C. racemosa. A) Average coverage and B) Natural productivity of each season

Although there was an increase in waves and ocean currents' intensity, the average percentage cover during the northern monsoon had the highest value. This was because most of the C. racemosa's lives were attached to a dead coral located at the edge of a coastline, rather than taking the impact of currents and waves. Furthermore, it was also influenced by numbers of predatory fishes such as herbivorous fish. This showed a decrease in the composition of the biota, including herbivorous fish that use C. racemosa as their food. Meanwhile, this factor also caused the high value of cover and natural productivity in the northern monsoon.

The variation of percentage cover and productivity values of C. racemosa were influenced by herbivorous biota consumption. Meanwhile, in the marine ecosystem's food chain, it is also known as a symbiosis which describes the relationship between producer and consumer. The $\mathrm{C}$. racemosa species is one of the producers and the habitat for important biota, including the herbivorous species. Kelly et al. (2017) reported that the herbivorous fish species that consume algae were 13 species, which include the Acanthurus triostegus, nigrofuscus, leucoparelus, and blochii, together with Zebrasoma flavencens, Scarus psittatus, S. rubroviolaceus, Chlorurus perspicillatus, and spilurus, Naso lituratus, N. unicornis, N. brevirostris as well as Calotomus carolinus. Furthermore, the presence of algae, including the C. racemosa species, is not only influenced by the changes of seasons; however, there are other factors, which include the association and food chain structure as well as the presence of herbivore fish. In addition, the herbivore biota composition also affects the cover condition. At the same time, the consumption rate of herbivorous fish ranges from 0.34 to 0.42 grams per $\mathrm{m} 2$ daily (Kelly et al. 2017), several herbivore groups associated with seaweed communities including sea urchins, crabs, amphipods, polychaetes and other species of invertebrates (Hay, 1997) are also consumed it.

The herbivorous fish tends to migrate towards the seagrass areas with less currents and wave's dynamic conditions. Therefore, the C. racemosa's community is not consumed optimally, which results in an increase in its percentage of cover. Meanwhile, the herbivorous fish's algae's consumption rate marks the level of algae composition in the nature. Furthermore, this phenomenon is supported by the research of Svensson et al. (2012), which reported that the herbivorous biota communities can control algae's growth in each growing season. However, high wave dynamics also cause slow fish movement to slow down so that the consumption decreases. In addition, macroalgae cover increased from 2 to 7 times due to a reduction in herbivore's consumption (Lamb et al. 2020; Karkarey et al. 2020). In line with Easton et al. (2018), the presence of herbivores and wave's energy are essential determinants of the algal community's condition.

However, the lowest cover value and natural productivity during the eastern monsoon is 0.326 $\mathrm{kg} / \mathrm{m} 2$. Meanwhile, this condition is related to the transition period between the northern (tides's increasing and current dynamics) and the eastern monsoon (decreasing tides and current dynamics). Furthermore, there is a peak period of current and highest waves in the northern monsoon. It is suspected that there is an intense scouring causing the colony of C. racemosa to erode during this period. While the $\mathrm{C}$. racemosa colonies attached to the sand's substrate are oxidized, those that grow on rock surfaces and corals are stronger to withstand the waves and currents. Caulerpa is equipped with a rhizoid system that sticks between the substrate gaps (Fagerburg et al., 2012; Garcia et al., 2011).

The wave's crests fluctuation and currents during the northern monsoon increased the water turbidity, which was supported by a TSS value of $76 \mathrm{mg} / \mathrm{l}$. At the same time, it became $73 \mathrm{mg} / \mathrm{l}$ during the east monsoon. The increased turbidity affects the intensity of light entering the water. Furthermore, an increase in the water turbidity is also influenced by currents intensity that grow during the northern monsoon, causing a mixing in the water column (Uchiyama et al. 2017; Whitney et al. 2005). Meanwhile, Gao et al. (2018) reported that the Caulerpa growth was affected by light conditions with at least $40 \mu \mathrm{mol} \mathrm{m}-2 \mathrm{~s}-1$. However, in the transitional season between the east and south monsoons, the water transparency conditions increase so that the light intensity also increases and supports the photosynthesis process. Vides (1999) reported that the natural productivity value and the cover are influenced by the photosynthesis's rate. 


\subsection{Morphometric of the C. racemosa}

A data is needed for predicting C. racemosa size in nature, together with the assumptions that where the morphometric value is high, its fertility rate is also high. Furthermore, C. racemosa morphometric size consists of 8 components each parameter (Figure 3), which include the diameter and length of the thallus ranging from 0.18 to $0.25 \mathrm{~cm}$ and 0.72 to $1.1 \mathrm{~cm}$, respectively. While for the size, the grains number as well as the diameter of the stolon obtained were in the range of 1.88 to $2.09 \mathrm{~cm}, 8$ to 9 grains and $0.48-1.01$ $\mathrm{cm}$. Furthermore, the weight of thallus biomass was 0.033 to 0.054 gram, of stolon grain biomass was between 0.021-0.041 g, while stolone biomass was between 0.019-0.053 gr.

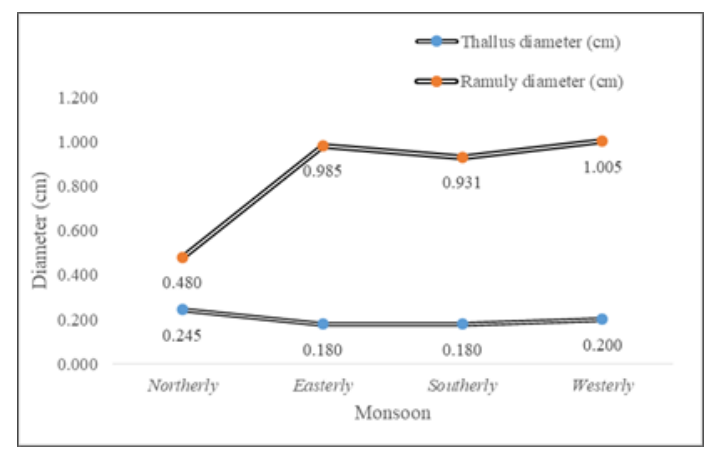

(a)

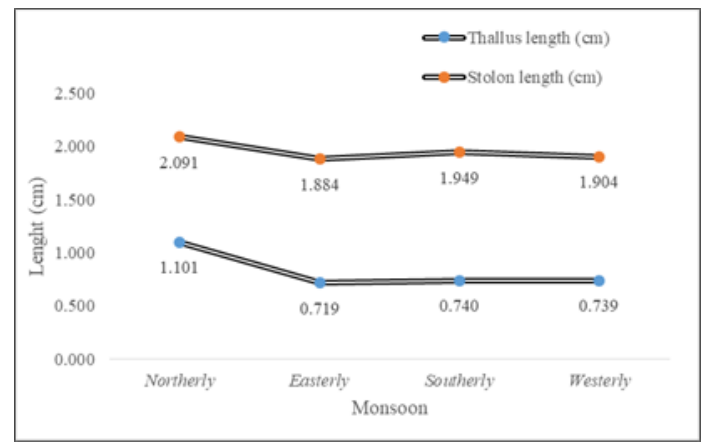

(b)

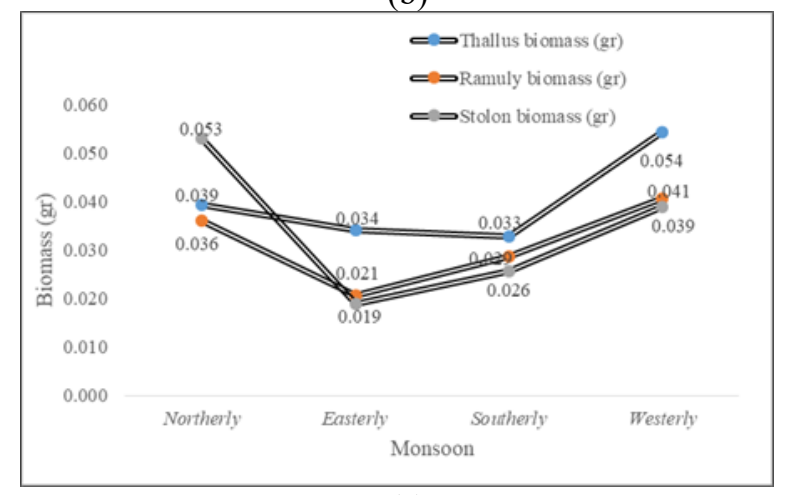

(c)

Fig. 4. Morphometric size of the C. racemosa; (a) thallus diameter and stolon grain diameter, (b) thallus length and stolon length, (c) thallus biomass, stolon grain biomass, and stolon grain biomass.

Figure 4 showed that the highest thallus diameter in the northern monsoon was $0.25 \mathrm{~cm}$, with an average of $0.201 \pm 0.03 \mathrm{~cm}$. While the length of the thallus $\mathrm{C}$. racemosa was $0.825 \pm 0.16 \mathrm{~cm}$ on average with the highest size was $1.1 \mathrm{~cm}$. The highest length, grains number, of the stolon value in the northern monsoon was $2.09 \mathrm{~cm}$ and nine items with an overall average of $1.95 \pm 0.08 \mathrm{~cm} 8 \pm 0.2$. However, where it observed from the highest stolons grain diameter, the western season is precisely with a $1.01 \mathrm{gr}$ value having an average of $0.85 \pm 0.22$ gr. Thallus and stolone grain biomass were also high during the western season with $0.054 \mathrm{~g}$ and $0.041 \mathrm{~g}$ values and an average of $0.040 \pm$ $0.01 \mathrm{~g}$ and $0.031 \pm 0.01 \mathrm{~g}$, respectively. Furthermore, the highest stolone biomass was also found during the northern monsoon with a 0.053 gr biomass value as well as an overall mean of $0.034 \pm 0.01 \mathrm{~g}$.

While the C. racemosa morphometric size in line with the sampling season fluctuated, the five out of 8 tested highest parameters were happened during the northern monsoon. Meanwhile, this phenomenon is similar to the cover percentage, which is also the highest. Previous studies by Engelen et al. (2005) reported that the thallus length has the highest one in January, where the season began with dynamics. However, after passing through the north to the east monsoon, there is a $\mathrm{C}$. racemosa rejuvenation growth. While this is indicated by the small morphometric size in the east monsoon and presumably C. racemosa has undergone regeneration or early development, plant morphometrics are smaller during early development. Furthermore, an increase in productivity occurs in the southern season due to its growth system.

Meanwhile, the morphometric parameters are interrelated, such as the increase in the thallus length followed by the development of the thallus diameter. However, the longer the thallus size, the longer the stolon is. Furthermore, the number of stolon grains increased as the length of the stolon increased. Hence, the longer the length of the stolon, increase in grains number, the heavier the size of the stolon biomass, followed by an increase in height, grains number, and stolon grain biomass. Meanwhile, from the description of the data above, it showed that each morphometric size value of $C$. racemosa were developed in line with the development of its biomass weight.

The stolon's length of C. racemosa ranged from 1.90 to $2.09 \mathrm{~cm}$, with an average of $1.95 \mathrm{~cm}$. While the stolons length generally ranges from 1.34 to $2.47 \mathrm{~cm}$ (Manas et al. 2015), the stolons' length of caulerpa reaches $2.528 \mathrm{~cm}$ (Vides, 2002). The results showed that the length of the stolon was close to the optimal size. Furthermore, the average thallus biomass was 0.04 gr (Vides, 2002), and the biomass range was between 0.014-0.027 gr. However, C. racemosa stolon grain diameter, tallus length, grains number has an average of $1.21 \mathrm{~cm}, 9.42 \mathrm{~cm}$, and $6.9 \mathrm{~cm}$, respectively (Estrada et al. 2020). Hence, in line with the the data, the morphometric value of $\mathrm{C}$. racemosa was classified as moderate.

\section{Conclusion}

Based on the results, natural factors in the form of seasonal changes and fluctuations in water dynamics 
were the main factors affecting C. racemosa's lifespan. The growth parameters, which include the percentage cover, its productivity, and the morphometrics, were affected by seasonal changes that was not significance. While the highest cover percentage was during the northern monsoon with an average value of $37.9 \pm$ $7.67 \%$, the lowest one was during the Eastern monsoon, which was $28.03 \pm 9.09 \%$. However, the highest and lowest natural productivity value of $\mathrm{C}$. racemosa were during the northern and eastern seasons with a value of $0.439 \pm 0.36 \mathrm{~kg} / \mathrm{m} 2$ and $0.326 \pm 0.37$ $\mathrm{kg} \mathrm{/} \mathrm{m} 2$, respectively. Furthermore, the best morphometric size was during the northern monsoon with a tallus dimension and the length value of 0.25 and 0.825 , together with stolon length, grain number of 2.09 and 9, respectively. While grain diameter $0.85 \mathrm{gr}$ and grain biomass $0.054 \mathrm{gr}$ and $0.041 \mathrm{gr}$ stolon best during the west season. Hence, this was caused due to different growth seasons and also by other organisms that use C. racemosa as a food source.

\section{Acknowledgment}

The author is grateful to both the Ministry of Education, Culture, Research, and Technology, and the Universitas Maritim Raja Ali Haji for the financial support. The author also thankful to Teluk Bakau Village, Malang Rapat, Berakit, Beralas Pasir, Pengudang, Sakera, and Dompak Villages who provided access to the researchers for the data collection in the field. Furthermore, the author is grateful to the researchers and survey team for the data collection of C. racemosa and other supporting data that assisted this study's completion properly.

\section{References}

1. Arnol. D, Kasim. M, Irawati. N. 2019.

Chaetomorpha crassa Density and Biomass are Attached to Kappaphycus alvarezii in Floating Net Mesh Networks in Lakeba Beach Waters Bau-Bau. Jurnal Manajemen Sumber Daya Perairan, 4 (2) : 145-154.

2. Burel. T, Grall. J, Schaal. G, Duff. M. L, Gall. E. A. 2019. Wave height vs. elevation effect on macroalgal dominated shores: an intercommunity study. Journal of Applied Phycology : 1-12. ournal of Applied Phycology. doi.org/10.1007/s10811019-01989-1.

3. Burt. J, Feary. D, Usseglio. P, Bauman. A, Sale. P. F. 2010. The Influence Of Wave Exposure On Coral Community Development On Man-Made Breakwater Reefs, With A Comparison To A Natural Reef. Bulletin Of Marine Science 86 (4) : 1-21. DOI: 10.5343/bms.2009.1013.

4. Chang. S. E, Stone. J, Demes. K, Piscitelli. M. 2014. Consequences of oil spills: a review and framework for informing planning. Ecology and Society 19 (2) : 1-26. doi.org/10.5751/ES-06406190226.
5. Chung. I. K, Sondak. C. F. A, Beardall. J. 2017. The future of seaweed aquaculture in a rapidly changing world. European Journal of Phycology 52 (4) : 495-505.

6. Das. L, Salvi H., Brahmbhatt B., Vaghela N., Kamboj R. D. 2018. Biomass and percent cover of marine macro algae at five south-western intertidal areas of Gulf of Kachchh. Phykos 48 (1): 46-57.

7. Denny. M, Gaylord. B. 2002. The mechanics of wave-swept algae. The Journal of Experimental Biology 205 : 13551362.doi.org/10.1080/09670262.2017.1359678

8. Duarte. C. M, Jiaping. W, Xiao. X, Bruhn. A, Jensen. D. K. 2017. Can Seaweed Farming Play a Role in Climate Change Mitigation and Adaptation?. Frontiers in Marine Science 4 (100) : 1-8. Doi: 10.3389/fmars.2017.00100.

9. Easton. E. E, Gaymer. C. F, Friedlander. A. M, Herlan. J. J. 2018. Effects of herbivores, wave exposure and depth on benthic coral communities of the Easter Island ecoregion. Marine and Freshwater Research 69 : 997-1006.

10. doi.org/10.1071/MF17064.

11. Engelen. A. H, Aberg. P, Olsen. J. L, Stam. W. T, Breeman. A. M. 2005. Effects of wave exposure and depth on biomass, density and fertility of the fucoid seaweed Sargassum polyceratium (Phaeophyta, Sargassaceae). British Phycological Society 40 (2) : 149-158.

12. DOI: $10.1080 / 09670260500109210$.

13. Estrada. J, Bautista. N. S, Maribel. L, Sese. D. 2020. Morphological variation of two common sea grapes (Caulerpa lentillifera and Caulerpa racemosa) from selected regions in the Philippines. Biodiversitas 21 (5) : 1823-1832. DOI: 10.13057/biodiv/d210508.

14. Fegerburg. W. R, Towlw. J, Dawes. C. J, Boettger. A. 2012. Bioahdhesion in Caulerpa Mexicana (Chlorophyta); Rhizoid-substrate adhesion. Phycological Society of America 47 : 1-6. DOI: 10.1111/j.1529-8817.2012.01113.x.

15. Gao. X, Choi. H. G, Park. S. K, Sun. Z. M, Nam. K. W. 2018. Assessment of optimal growth conditions for cultivation of the edible Caulerpa okamurae (Caulerpales, Chlorophyta) from Korea. Journal of Applied Phycology 31 (3) : 1-9. DOI: 10.1007/s10811-018-1691-z.

16. Garcia. C. F, Cortes. J, Alvarado. J. J, Ruiz. J. N. 2012. Physical factors contributing to the benthic dominance of the alga Caulerpa sertularioides (Caulerpaceae, Chlorophyta) in the upwelling Bahía Culebra, north Pacific of Costa Rica. Revista de Biología Tropical 60 (2) : 93-107.

17. Harley. C. D. G, Anderson. K. M, Demes. K. W, Jorve. J. P, Kordas. R. L, Coyle. T. A, Graham. M. H. 2012. Effects Of Climate Change On Global Seaweed Communities. J. Phycol 48 : 1064-1078. DOI: $10.1111 /$ j.1529-8817.2012.01224.x. 
18. Hay. M. E. 1997. The ecology and evolution of seaweed-herbivore interactions on coral reefs. Coral Reefs $16: 67-76$. DOI: $10.1007 / \mathrm{s} 003380050243$.

19. Johsson. P. R, Granhag. L, Moschella. P. S, Aberg. P, Hawkins. S. J, Thompson. R. C. 2006. Interactions between Wave Action and Grazing Control the Distribution of Intertidal Macroalgae. Ecology 87 (5) : 1169-1178. DOI: 10.1890/00129658(2006)87[1169:ibwaag]2.0.co;2.

20. Karkarey. R, Rathod. P, Arthut. R, Yadav. S, Theo. A, Alcoverro. T. 2020. Wave exposure reduces herbivory in post-disturbed reefs by fltering species composition, abundance and behaviour of key fsh herbivores. Scientific Reports 10 (1): 1-14. DOI: 10.1038/s41598-020-66475-y.

21. Kelly. E. L. A, Eynaud. Y, Williams. I. D, Sparks. R. T, Dailer. M. L, Sandin. S. A, Smith. J. E. 2017. A budget of algal production and consumption by herbivorous fish in an herbivore fisheries management area, Maui, Hawaii. Ecosphere 8 (8) : 1-16. doi/10.1002/ecs2.1899/full.

22. Kumar. G. S, Umamaheswari. S, Kavimani. S, Ilavarasan. R. 2019. Pharmacological Potential of Green Algae Caulerpa: A Review. IJPSR 10 (3): 1014-1024. DOI:10.13040/IJPSR.09758232.10(3).1014-24.

23. Lamb. R. W, Smith. F, Witman. J. D. 2020. Consumer mobility predicts impacts of herbivory across an environmental stress gradient. Ecology 101 (1) : 1-17. doi.org/10.1002/ecy.2910.

24. Llamas. E. G, Bucol. A. B, Wagey. B. T. 2018. Standing-Stock Biomass And Diversity Of Caulerpa (Chlorophyta) In Solong-On, Siquijor Island, Philippines. Jurnal Ilmiah Sains 18 (2) : 8596. DOI: 10.35799/jis.18.2.2018.20821.

25. Lodola. A. 2013. Distribution and abundance of the tropical macroalgae Caulerpa racemosa var. cylindracea (Chlorophyta: Caulerpaceae) and Asparagopsis taxiformis (Rhodophyta: Bonnemaisoniaceae) in the upper infralittoral fringe of Linosa island. Scientifica Acta 7 (1) : 311.

26. Manas. H. M, Deshmukhe. G, Venkateshwarlu. G, Chakraborty. S. K, Jaiswar. A. K, Pankajkumar. H, Mugaonkar, Dar. S. A. 2015. Morphological comparison of different Caulerpa J. V. Lamouroux species along Maharashtra and Gujarat coasth, India. Indian Journal of Geo-Marine Sciences 44 (5) : 732-737.

27. Melsasail. K, Awan. A, Papilaya. P. M, Rumahlatu. D. 2018. The ecological structure of macroalgae community on various zones in the coastal waters of Nusalaut Island, Central Maluku District, Indonesia. AACL Bioflux 11 (4) : 957966.

28. Nagaraj. S. R, Osborne. J. W. 2014. Bioactive compounds from Caulerpa racemosa as a potent larvicidal and antibacterial agent. Front. Biol 9 (4) : 300-305. DOI 10.1007/s11515-014-1312-4.
29. Notowinarto, Ramses, Destaria. 2015. Morphometrics Growth of eucheuma cottoni Thallus at Distric Bulang Island Area . Prosiding Seminar Nasional Biologi : 142-148

30. Pandya. K. Y, Patel. R. V, Jasrai. R. T, Barahmbhatt. N. 2017a. Comparison Of Bioremediation Efficiency Of Caulerpa Racemosa and Ulva Lactuca From Industrial Dye Effluents. International Journal of Recent Scientific Research 8 (7) : 18661-18672. DOI: 10.24327/IJRSR.

31. Paul. N. A, Nys. R. D. 2008. Promise and pitfalls of locally abundant seaweeds as biofilters for integrated aquaculture. Aquaculture 281 : 49-55. doi:10.1016/j.aquaculture.2008.05.024.

32. Pereira. L. 2018. Seaweeds as Source of Bioactive Substances and Skin Care Therapy Cosmeceuticals, Algotheraphy, and Thalassotherapy. Cosmetics 5, (68) : 1-41, doi:10.3390/cosmetics5040068

33. Rehena. J. F. 2009. Produktivitas Biomassa dan Laju Pertumbuhan Rumput Laut Eucheuma cottonii di Perairan Wael Seram Bagian Barat Provinsi Maluku. Journal of Biological Researches 14 (2) : 197-202. DOI: 10.23869/bphjbr.14.2.200911.

34. Sunny. A. R. 2017. A review on effect of global climate change on seaweed and seagrass. International Journal of Fisheries and Aquatic Studies 5 (6) : 19-22.

35. Svensson. C. J, Baden. S, Moksnes. P. O, Aberg. P. 2012. Temporal mismatches in predatorherbivore abundance control algal blooms in nutrient-enriched seagrass ecosystems. Marine Ecology Progress Series 471 : 61-71. doi: 10.3354/meps 10014 .

36. Pusvariauwaty, Notowinarto, Ramses. 2015. Pertumbuhan morfometrik Thallus Rumput Laut Eucheuma Cottoni di Perairan Pulau Bulang Batam. SIMBIOSA 4 (2) : 91-96

37. Tapotubun. A. M, Matrutty. T. E, Riry. J, Tapotubun. E. J, Fransina. E. G, Mailoa. M. N, Riry. W. A, Setha. B, Riewpassa. F. 2020. Seaweed Caulerpa sp position as functional food. Earth and Environmental Science 517 : 1-8. doi:10.1088/1755-1315/517/1/012021.

38. Vides. L. C. 2002. Morphological Plasticity of Caulerpa prolifera (Caulerpales, Chlorophyta) in Relation to Growth Form in a Coral Reef Lagoon. Botanica Marina 45 (2) : 123-129. DOI: 10.1515/BOT.2002.013.

39. Yuewen. D, Adzigbli. L. 2018. Assessing the Impact of Oil Spills on Marine Organisms. Journal of Oceanography and Marine Research 6 (1) : 1-7. doi: 10.4172/2572-3103.1000179 